\title{
Introduction: Arbitrary Constructions and Real Consequences of the Self and Other
}

\author{
Marissa Sonnis-Bell
}

No one can deny the persisting continuities of long traditions, sustained habitations, national languages, and cultural geographies, but there seems no reason except fear and prejudice to keep insisting on their separation and distinctiveness, as if that was all human life was about. Survival in fact is about the connections between things; in Eliot's phrase, reality cannot be deprived of the "other echoes [that] inhabit the garden". ${ }^{1}$

It has become clear that every version of an 'other', wherever found, is also the construction of a 'self'.'

Scholars across disciplines have long been interested in societal constructs of separation and distinctiveness, as seen in Said's work quoted above. It has long been sought to reveal what makes a stranger strange, a foreigner foreign and an alien alienated: the identifiable components which allow separation through distinction. What unites the terms Stranger, Alien, Foreigner, after which this book is titled, is that they all stem from the process of "othering", or alterity, and are often framed within constructs of the dominant self and the minority other, as hinted to in the second quote above from Clifford. ${ }^{3}$

1 Edward Said, Culture and Imperialism (Vintage, 1994), 408.

2 James Clifford. Writing Culture (Berkeley: University of California Press, 1986, Clifford, 1986), 23 .

3 Ibid. 
What I hope to emphasize in this introduction, echoed throughout the chapters of this book, is manifold. Firstly, the self and the other should be seen as part of a whole, in that one cannot exist without the other, and the creation of one is often in the context of the creation of the other. Secondly, the distinction between the self and other is arbitrarily defined in that it is fleeting and shifts with what is convenient, whether it be race, religion, class, ethnicity, or geography. This arbitrariness is most evident in spaces of exception and liminality where the process of othering does not quite map onto conventional notions of othering, as I will elucidate. Finally, while the process of othering might be considered arbitrary, the consequences are very real and tangible, as will be illustrated. For purposes of introduction, I touch on some of the prominent thinkers in the field of othering, or alterity, and suggest how the chapters of this book interact with the field and the themes outlined herein.

It has been argued that the process of 'Othering' is visible across societies, with both psychological and philosophical implications. From early childhood, as Sibley demonstrates, ${ }^{4}$ there is 'confirmation of the boundaries of the self and situating the self in the social world through the sorting of people and things into good and bad categories'. This process of othering is thus a fundamental component to identity formation and continues with the ongoing development of one's identity. Understanding what we are not is inherent to understanding what we are. As Kearney points to 'Most Western discourses of identity are predicated upon some unconscious projection of an Other who is not "us". 5 Therefore, to understand this dialectically, one can see the Self/Other to be inherently intertwined and involved in the progress of identity formation. Defining the Other, we also define the Self, and in defining what is not of 'us' we are better equipped for self-preservation. ${ }^{6}$

To further understand the process of othering, one must also recognize that it is also often seen to be imbued with a power dynamic, in which the Self is the dominant and hegemonic 'in-power' entity, while the Other is the

4 David Sibley ‘The Binary City’, Urban Studies 38.2 (2001): 244.

5 Richard Kearney, 'Strangers and Others: From Deconstruction to Hermeneutics', Critical Horizons 3.1 (2002): 14.

6 James Clifford, Writing Culture, 26. 
alternate minority. ${ }^{7}$ The labels to which these apply are often scale dependent, as on a global scale the dominant in-power may be Western as often discussed throughout this book and introduction, while on a national scale it may be white or European, for example. The othering of minority populations is illustrated in the dominant discourses of 'invasion' by a minority other, in Tommaso Trillò's case the Muslim migrant (as discussed in chapter 8), or in Hanna Jagtenberg's case a foreign South African minority (chapter 5). This is an instance in which definitions of the Other might be along the lines of 'a member of a dominated out-group, whose identity is considered lacking and who may be subject to discrimination by the in-group' ${ }^{8}$

However, while it is true that othering is essential to identity formation in Western discourse, even the very definition of 'Western' is wrapped up in distinctions that are arbitrarily defined (yet historically entrenched), vague and complex. This is evident in the body of work on Orientalism by the founder of the field of post-colonialism, Edward Said, whereby he demonstrates the discursive construction of the 'Orient' (or East) by the 'Occident' (or the West) (Orientalism 1973). Yet for lack of a better distinction, I continue with this ambiguous terminology of 'West' used loosely to refer to the developed world.

While Othering has so far been discussed in the context of Western discourse, it is apparent in non-Western discourse too. As David Bell points out in chapter 2, Othering is commonplace in many non-Western societies too, where self-chosen names such as those of the Kulina tribe, translate to 'person', ${ }^{9}$ with the assumption of Others being non-persons, non-human, or alien, to draw upon the title of this collection.

The various chapters of this book do primarily draw from Western discursive perspectives, while highlighting the complexity of Other perspectives too, such as Michelle Ryan's in-depth examination through interviews of non-European refugee experiences in Ireland (chapter 7). Despite this brief departure into non-Western thinking, the chapters mainly draw upon Western experiences to interrogate such ideas, such as the discursive construction, treatment and experiences of migrants in Europe, specifically Italy, Croatia, and Northern Europe. Although in doing so, while from a Western perspective, many authors attempt to deconstruct the oversimplified binaries of the Self/Other. The point is to understand the experiences of the other and the processes in which

7 Jean-Francois Staszak, 'Other/otherness' in International Encyclopedia of Human Goegraphy, ed 2008 Rob Kitchin and Nigel Thrift (Oxford: Elsevier, 2009), 2.

8 Staszak. 'Other/Otherness', 2.

9 Donald Pollock, 'Personhood and Illness Among the Kulina', Medical Anthropology Quarterly 10.3 (1996): 323 . 
othering occurs. Predominantly, the strangers, aliens and foreigners that we speak of come in the form of migrants, immigrants, and refugees, with the caveat of the third chapter in which Marissa Bell deals with the corporate other, adding an even more alien, in the non-human sense, dimension to the topics covered in this book.

\section{The Arbitrariness of How the Other Is Constructed}

Through the various perspectives on Othering shown throughout this book, the intention is to illustrate that the construction of the Other, in line with previous work, is arbitrary and complex, but with very real consequences. The uncertain patterns by which difference is created flow along multiple lines, of religion, ethnicity, race, nationality, class and geographic divides, seemingly fleeting and contradictory. While the Other tends to be constructed in opposition to a dominant hegemonic Self, there are instances in which the majority is also a minority along intersectional lines, or where the minority are the ones constructing the Other, depending on which perspective is being examined.

In the case of Swiss migrants to China and Northern Europe (chapter 4), Aldina Camenisch and Seraina Müller show how a socially privileged, economically advantaged, group of white European migrants are seen to be the Other. This is also echoed in Hanna Jagtenberg's work (chapter 5 ) in which a white, religious, educated but South African minority is discriminated against by also white, but often less educated, less religious, and most importantly Australian and therefore dominant majority. In other instances, rural, white, economically disadvantaged Americans construct a corporate Other in opposition to a spontaneously constructed yet cohesive community Self. These three cases are examples in which groups occupy liminal 'third positions' as Aldina Camenisch and Seraina Müller define, spaces of exception where the arbitrariness of categorical othering is most evident.

\section{3}

\section{The Real Consequences of Othering}

Yet despite being arbitrary, the process of Othering has very real, tangible consequences. Just as the Other can be defined according to multiple and complex lines of gender, sexuality, race, ethnicity, geography, and many others, so can the array of consequences. Discrimination on any of these bases and beyond has implications that span from emotional distress, to psychological 
trauma, and physical consequences such as access to healthcare, financial support, to name but a few. On a broader scale, the process of othering has tangible implications for human rights, as demonstrated theoretically by David Bell (chapter 2) in his analysis of the suspension of human rights on a cultural level in cases for those given the label 'terrorist', a label only given by hegemonic society to those deemed as deviant ad dangerous, ${ }^{10}$ mostly ethnically Middle Eastern, Muslim others. ${ }^{11}$ The tangible consequences are also exemplified through Michelle Ryan's empirical work (chapter 7) on Direct Provision in Ireland, a prison-like institution where refugees and asylum seekers are sent before officially registered as migrants and able to work, where their movements, activities and freedoms are restricted, sometimes up to five years.

Lana Pavić, in chapter 6, deconstructs ethical-moral responsibilities of people to these refugees and migrants. In her political-philosophical discussion, Lana Pavić points to the responsibility to host migrant/strangers as guests. Most importantly, she states, 'As long as the guest acts peacefully, one is not to be treated with hostility, locked up or tortured, ${ }^{12}$ and yet this is precisely what we see in Michelle Ryan's depiction of vulnerable refugees and asylum seekers; they are housed in confinement detention centres until receiving the correct paperwork to be considered legally part of Irish society (chapter 7 ). While this may come as a surprise, it is very much embedded within modern society, as noted based on the work of Foucault: 'Reason (or the Same) has progressively identified, named, stigmatized and sought to exclude, [through either banishment or incarceration], 'Unreason' (or the Other)..$^{13}$ The consequences of this are spatial relationships such as, 'physical divides, segregation and exclusion, that inscribes into bricks and mortar, a distancing of the Other from the Same. ${ }^{14}$ What we see being done to refugee others, Foucault noted being inflicted upon the mentally ill, the sick and the criminal. These patterns of exclusion or demarcation are visible at multiple scales. A look at any major American metropolitan area, from Baltimore to Buffalo, would reveal stark racial and economic contrasts.

\footnotetext{
10 David Sibley, Geographies of Exclusion (London: Routledge, 1996).

11 Noam Chomsky, Hegemony Or Survival? (London: Hamish Hamilton, 2003), 10.

12 Lana Pavić, Chapter 6 of this book.

13 Chris Philo, 'Michel Foucault', in Key Thinkers on Space and Place, eds Phil Hubbard and Rob Kitchin. (London: Sage, 2010), 126.

14 Chris Philo, 'Michel Foucault', 127.
} 
My intention for this introduction was to elucidate the invisible threads that tie the diverse chapters of this book together. Rather than end on a negative note of incarceration and spaces of exclusion, I want to return to the beginning quote of this introduction, to shed some positive light on Othering. Namely, that the benefit of having the other, the other whose "echoes inhabit the garden"15, is that not only such Other forces us to confront and further reflect on our Self (defined along any line of individuality, intersectionality, nationality etc.), but it also forces us beyond preliminary and superficial notions of the solitary self to enrich human interaction through the real complexities of a social world

While each chapter addresses some specific aspect of the process of Othering, many seek to transcend the Self/Other binary by showing how intertwined they are. In this regard, the Other is seen as inherently constituted within the Self, and vice versa. To take this one step further, the boundary between the two is often capricious and shifting based on lines drawn and given importance only through context, whether this be in regards to race, religion, class, ethnicity, nationality, as all addressed within this book. Such distinctions within such social contexts force the reader to reflect on their own self/other. Furthermore, it might serve as an understated call to action, for in highlighting the very real consequences of othering, we draw attention to the deep and troubling issues which stand as fault lines for our time. For some, these fault lines are a matter of emotional strength and quality of life, while for others they are a matter of life and death: distinguishing the importance, just like distinguishing the line between Self and Other, shall now be left up to the reader.

\section{Bibliography}

Chomsky, Noam. Hegemony Or Survival? London: Hamish Hamilton, 2003.

Clifford, James. Writing Culture. Berkeley: University of California Press, 1986.

Kearney, Richard. 'Strangers and Others: From Deconstruction to Hermeneutics'. Critical Horizons 3.1 (2002): 7-36.

Philo, Chris. 'Michel Foucault'. In Key Thinkers on Space and Place, edited by Phil Hubbard and Rob Kitchin, 121-128, London: Sage, 2010. 
Pollock, Donald. 'Personhood and Illness among the Kulina', Medical Anthropology Quarterly 10.3 (1996): 319-341.

Said, Edward. Culture and Imperialism. New York: Vintage, 1994.

Sibley, David. Geographies of Exclusion, London: Routledge, 1996.

Sibley, David. 'The Binary City'. Urban Studies 38.2 (2001): 239-25o.

Staszak, Jean-Francois. 'Other/Otherness' In International Encyclopaedia of Human Geography, edited by Rob Kitchin and Nigel Thrift. Oxford: Elsevier, 2009. 